\title{
Bone flap preservation in abdominal wall after decompressive craniectomy in head injury: A single institute experience
}

\author{
Pavan Kumar, Ashok Kumar, Gaurav Jaiswal, Tarun Kumar Gupta \\ Department of Neurosurgery, R.N.T. Medical College, Udaipur, Raj, INDIA
}

\begin{abstract}
Objective: The objective of this study is to study factors associated with infection of calvarial bone flap preserved in subcutaneous tissue of abdominal wall after decompressive craniectomy (DC) in head injury. Associated factors include age, sex, nutrition of patient, GCS of patient at time of surgery, vacuum drain placement, type of paramedian abdominal incision, site of decompressive craniectomy and associated comorbid conditions. Method: This is a prospective study carried out in department of neurosurgery, tertiary care centre of southern Rajasthan (India) from July 2016 to December 2018. Total of 66 patient with head injury were enrolled, who underwent DC and bone flap preservation in abdominal wall. Result: Out of 112 patients who underwent DC in this study period 66 were included in this study. Out of 66 patient 7(10.6\%) patient develop bone flap infection. Bone flap infection was more in poor nutrition patient, poor GCS (5-8), patient in which vacuum drain was not placed, patient with bifrontal decompressive craniectomy and associated comorbid condition. Conclusion: Bone flap preservation in subcutaneous abdominal wall after DC is safe and efficient. Cranioplasty with autologous bone graft has lower cost, good cosmetic results and is well accepted by patient.
\end{abstract}

Key words: Bone flap, decompressive craniectomy, infection

\section{Introduction}

Decompressive craniectomy (DC) defined as the removal of a large area of skull with opening of dura to increase the volume of cranial cavity, facilitating a reduction in ICP.

DC is surgical option in the management of refractory intracranial hypertension when maximal medical treatment has failed to control it, especially in head injury, stroke, and post-operative edema after brain surgery.

The technique of storing calvarial bone flap in subcutaneous abdominal wall offer a theoretical advantage in that patient's own body provide a storage environment, thereby reducing graft devitalization. 
Other preservation techniques include deep freezing, preservation in bactericidal solution and preservation in a subgaleal pouch.

\section{Aim and objective}

The objective of this study is to study factors associated with infection of calvarial bone flap preserved in subcutaneous tissue of abdominal wall in head injury patient.

Associated factors include age, sex, nutrition of patient, GCS of patient at time of surgery, vacuum drain placement, type of paramedian abdominal incision (transverse/ longitudinal), site of DC (FTP or bifrontal) and associated comorbid conditions (obesity and diabetes).

\section{Material and method}

This is a prospective study carried out in department of neurosurgery, tertiary care centre of southern Rajasthan (India) from July 2016 to December 2017.

Out of 112 patients who underwent decompressive craniectomy in this study period 66 patient with head injury were enrolled, who underwent decompressive craniectomy with bone flap preservation in abdominal wall.

Inclusion criteria include-(1) DC in patient of head injury, (2) age between 10 and 70 year.

Exclusion criteria include - (1) comminuted fracture of skull, (2) patient expired early (within 5 days) after DC, (3) DC in patient of stroke or post-operative edema after brain surgery, and (4) GCS $\leq 4$.

The abdomen must be prepared before the craniectomy was performed to avoid flap contamination. A paramedian abdominal incision, with dissection of a space under the subcutaneous tissue and placing of the bone flap was made. Bone flap placement in parietal wall was same side of DC (e.g right side DC bone flap was placed in right side of abdominal wall) because if post traumatic hydrocephalous develop then it became easy to do VP Shunt in opposite side.

\section{Results}

A total of 112 decompressive craniectomy done in study period of 18 months. Out of 112 patient with DC 66 enrolled in study and other are excluded. Out of 66 patient enrolled in study $7(10.6 \%)$ patient develop bone flap infection preserved in abdominal wall.

Bone flap infection was more in poor nutrition patient $(21.42 \%)$ vs good nutrition patient(7.69\%), GCS 5-8 (13.88\%) vs GCS $>8(6.66 \%)$, patient in which vacuum drain was not placed $(21.05 \%)$ vs vacuum drain placed(6.38\%), bifrontal $\mathrm{DC}(20 \%) \quad$ vs frontoparietotemporal $\mathrm{DC}(9.83 \%)$ and associated comorbid condition as obesity (16.67\%) and diabetes(25\%) shown in Table 1.

Age, sex and type of paramedian abdominal incision (transverse or longitudinal) was not significantly associated with infection rate (Table 2).

Most of bone flap infection develop between 8-15 days after surgery. In most of cases autologous bone cranioplasty done between 3-6 month with good result.

Incision and infected bone flap shown in figure 1-5.

Decompressive craniectomy done for acute subdural haematoma and contusion of brain. 


\section{TABLE 1}

\begin{tabular}{|l|l|l|}
\hline Associated factor & $\begin{array}{l}\text { No. of patient } \\
\text { (Total No. of } \\
\text { pt.-66) }\end{array}$ & $\begin{array}{l}\text { No. of pt. } \\
\text { with bone flap } \\
\text { infection (\%) }\end{array}$ \\
\hline $\begin{array}{l}\text { Nutrition status } \\
\text { Good } \\
\text { Poor }\end{array}$ & 52 & $4(7.69)$ \\
\hline $\begin{array}{l}\text { GCS } \\
5-8\end{array}$ & 36 & $3(21.43)$ \\
$>8$ & 30 & $5(13.88)$ \\
\hline $\begin{array}{l}\text { Vacuum drain } \\
\text { placed } \\
\text { not placed }\end{array}$ & 47 & $3(6.66)$ \\
\hline $\begin{array}{l}\text { Site of DC } \\
\text { FPT }\end{array}$ & 19 & $4(6.38)$ \\
Bifrontal & 5 & $6(21.05)$ \\
\hline $\begin{array}{l}\text { Comorbid } \\
\text { condition } \\
\text { Obesity }\end{array}$ & 6 & $1(20.00)$ \\
Diabetes & 4 & $1(16.67)$ \\
\hline
\end{tabular}

\section{TABLE 2}

\begin{tabular}{|l|l|l|}
\hline Associated factor & $\begin{array}{l}\text { No. of patient } \\
\text { (Total No. of } \\
\text { pt.-66) }\end{array}$ & $\begin{array}{l}\text { No. of pt. } \\
\text { with bone flap } \\
\text { infection (\%) }\end{array}$ \\
\hline Age(year) & 11 & $1(9.09)$ \\
$10-20$ & 36 & $4(11.11)$ \\
$21-40$ & 16 & $2(12.5)$ \\
$41-60$ & 3 & 0 \\
$61-70$ & 46 & $5(10.86)$ \\
\hline Sex & 20 & $2(10.00)$ \\
Male & \multicolumn{2}{|l}{} \\
Female & \multicolumn{2}{|l}{} \\
\hline Paramedian \\
abdominal \\
incision
\end{tabular}

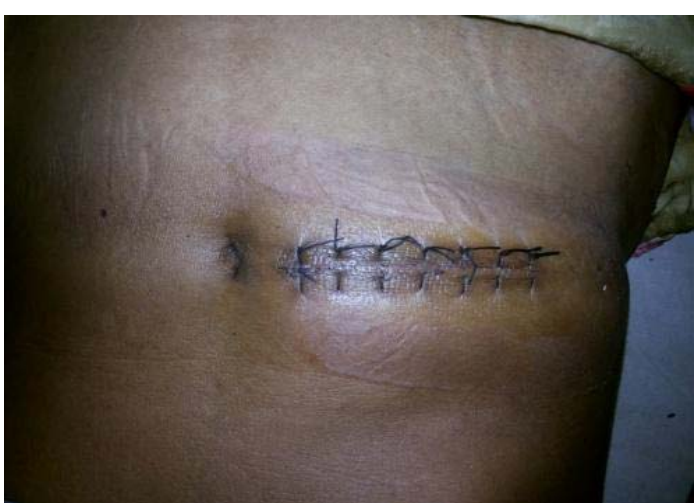

Figure 1 - Transverse paraabdominal incision

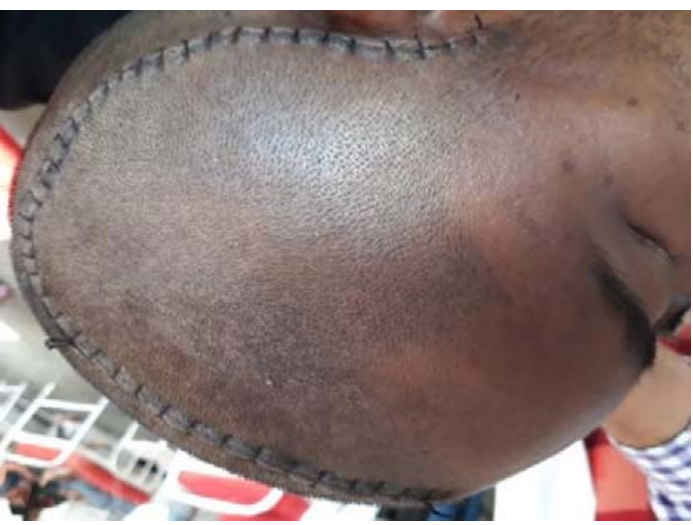

Figure 2 - FTP decompressive craniectomy incision

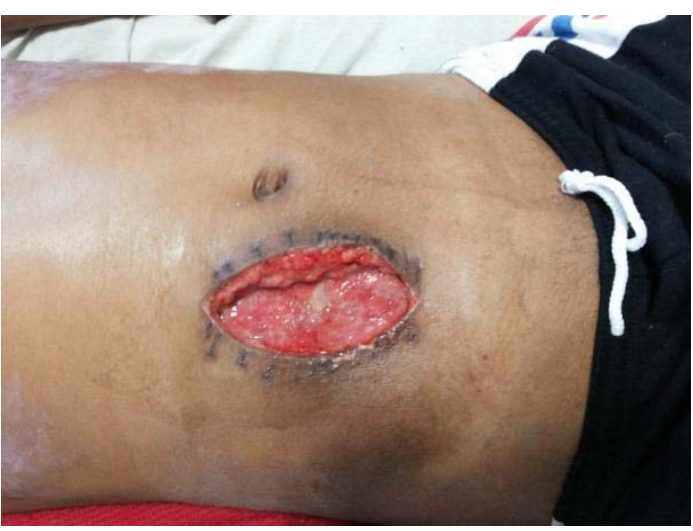

Figure 3 - Infected paraabdominal wound 


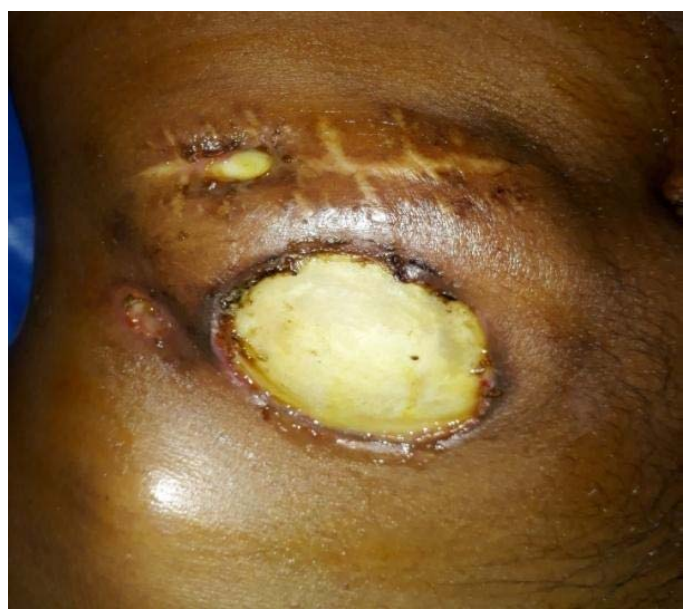

Figure 4 - Infected abdominal wound with exposed bone flap

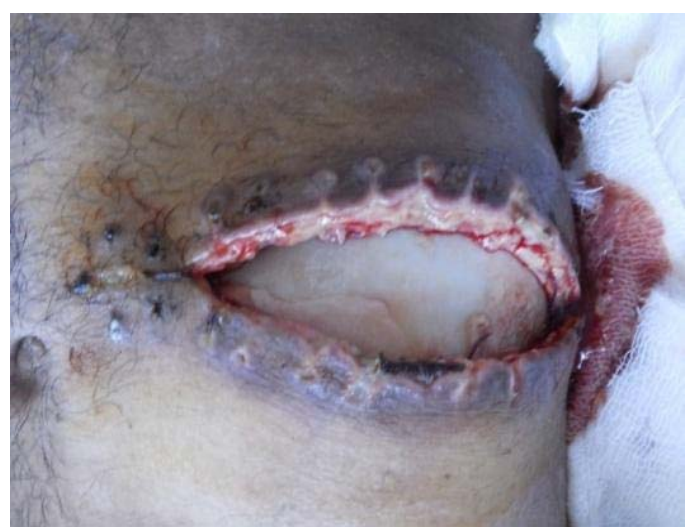

Figure 5 - Infected abdominal wound with bone flap

\section{Discussion}

Decompressive craniectomy (DC) is performed in medically refractory situations involving elevated intracranial pressure (ICP), such as intracerebral bleeding, traumatic brain injury (TBI), and ischemic brain lesion leading to severe brain swelling $(1,2)$.

Given the ultimate goal of cranioplasty to reproduce the structure and function of absent calvaria to the greatest degree possible, the merits of autologous bone are obvious, including marked strength and elasticity, biocompatibility, general availability, and resistance to infection. Given the low cost of conservation, lower rates of infection compared with many other types of prostheses, and assured biocompatibility, the autologous cranial flap remains the gold standard in calvarial repair (3).

In the literature, four possible fates are possible for the bone flap after craniotomy: 1) placing of the bone under the subcutaneous abdominal tissue, 2) preservation of the bone in the subgaleal space on the edges of the craniotomy, 3) freezing of the bone flap and 4) dumping the flap for delayed cranioplasty with synthetic material or bone graft resulting from cranial vault split.

Movassaghi et al. (4) evaluated the efficacy of bone flap placement in the abdomen of 53 patients, being successful in 49 with one time reconstruct. One patient needed a surgical revision for cosmetic purposes and three had flap infection, one of them with the flap still in the abdomen. They concluded that the abdominal bone flap preservation is effective and has a low complication rate.

Hauptli et al. (5) related 43 cases of bone flap placement in the subcutaneous abdominal tissue, obtaining only three unfavorable outcomes: one patient presented bone infection and two had local absorption. They emphasized that this technique was better then the freezing with less bone loss by absorption.

Tybor et al. (6) after studying 36 cases of flap implants preserved in the abdominal wall (median 14 days between the surgeries), had one case of flap infection in 28 implants. Two patients had the flap removed out of the 
abdomen for subcutaneous hematoma other by abdominal wall inflammation. They considered that bone flap preservation in the abdomen has cosmetic, financial, and technical advantages when compared to the use of synthetic prosthesis and has low inflammatory complication events.

In our study bone flap infection seen in $10.6 \%$ of cases. Higher bone flap infection was associated with poor nutritional status of patient, low GCS (5-8) at time of surgery, vacuum drain not placed in abdominal wall, bifrontal decompressive craniectomy and associated comorbid condition as obesity and diabeties. Patient with GCS $>8$ recover early. In patient with poor GCS (5-8) bone lap infection was $13.88 \%$ compare to good GCS $(>8)$ patient $(6.66 \%)$. Vacuum drain placement in abdominal wall prevent haematoma formation under bone flap so it prevent infection as seen in which vacuum drain placed infection rate was $6.38 \%$ as compare to patient in which vacuum drain not placed (21.05\%). Shape of bifrontal craniectomy bone flap is more convex compare to FTP craniectomy bone flap so more dead space available under bifrontal bone flap for haematoma formation leading to infection. Infection rate in bifrontal bone flap was $20 \%$ compare to $9.83 \%$ in FTP craniectomy bone flap. In our study bone flap infection was not significantly associated with age and sex of patient.

\section{Conclusion}

Bone flap infection is more common in poor nutrition patient, poor GCS (5-8), patient in which vacuum drain not placed, site of DC (FTP or bifrontal) and patient with associated comorbid condition. Bone flap preservation in subcutaneous abdominal wall after decompressive craniectomy is safe and efficient. Cranioplasty with autologous bone graft has lower cost, good cosmetic results and is well accepted by patient.

\section{Correspondence}

Dr. Pavan Kumar

323 P G Boy's hostel,

R N T Medical College, Udaipur,

Rajasthan, India

Emai: pavanbarh@rediffmail.com

Phone: +919588229198

\section{References}

1. Diedler J, Sykora M, Blatow M, Jüttler E, Unterberg A, Hacke W. Decompressive surgery for severe brain edema. J Intensive Care Med 24:168-178, 2009

2. Meyer MJ, Megyesi J, Meythaler J, Murie-Fernandez M, Aubut JA, Foley N, et al. Acute management of acquired brain injury part II: an evidence-based review of pharmacological interventions. Brain Inj 24:706-721, 2010

3. Artico M, Ferrante L, Pastore FS, Ramundo EO, Cantarelli D, Scopelliti D, et al: Bone autografting of the calvaria andcraniofacial skeleton: historical background, surgical results in a series of 15 patients, and review of the literature. Surg Neurol 60:71-79, 2003.

4. Movassaghi K, Ver Halen J, Ganchi P, Amin-Hanjani S, Mesa J, Yaremchuk MJ. Cranioplasty with subcutaneously preserved autologous bone grafts. Plast Reconstr Surg 2006;117(1):202-6.

5. Hauptli J, Segantini P. New tissue preservation method for bone flaps following decompressive craniotomy. Helv Chir Acta 1980;47(1-2):121-4.

6. Tybor K, Fortuniak J, Komunski P, Papiez T, Andrzejak $\mathrm{S}$, Jaskólski D, et al. Supplementation of cranial defects by an autologous bone flap stored in the abdominal wall. Neurol Neurochir Pol 2005;39(3):220-4. 